\title{
China's future food demand and its implications for trade and environment
}

\author{
Hao Zhao $\mathbb{1}^{1,2,3}$, Jinfeng Chang $\mathbb{1}^{3,4}$, Petr Havlík $\mathbb{1}^{3 凶}$, Michiel van Dijk $\mathbb{1}^{3,5}$, Hugo Valin $\mathbb{1}^{3}$, \\ Charlotte Janssens ${ }^{3,6}$, Lin Ma ${ }^{1}{ }^{\circledR}$, Zhaohai Bai ${ }^{1}{ }^{1}$, Mario Herrero ${ }^{7}{ }^{7}$, Pete Smith ${ }^{8}{ }^{8}$ and \\ Michael Obersteiner (103,9
}

\begin{abstract}
Satisfying China's food demand without harming the environment is one of the greatest sustainability challenges for the coming decades. Here we provide a comprehensive forward-looking assessment of the environmental impacts of China's growing demand on the country itself and on its trading partners. We find that the increasing food demand, especially for livestock products ( $-16 \%-30 \%$ across all scenarios), would domestically require $-3-12$ Mha of additional pasture between 2020 and 2050 , resulting in $\sim 2 \%$ to $+16 \%$ growth in agricultural greenhouse gas (GHG) emissions. The projected $-15 \%-24 \%$ reliance on agricultural imports in 2050 would result in $\sim 90-175 \mathrm{Mha}$ of agricultural land area and $\sim 88-226 \mathrm{MtCO}_{2}$-equivalent yr-1 of GHG emissions virtually imported to China, which account for $-26 \%-46 \%$ and $13 \%-32 \%$ of China's global environmental impacts, respectively. The distribution of the environmental impacts between China and the rest of the world would substantially depend on development of trade openness. Thus, to limit the negative environmental impacts of its growing food consumption, besides domestic policies, China needs to also take responsibility in the development of sustainable international trade.
\end{abstract}

C hina has undergone remarkable social and economic development over the past two decades to become the world's second largest economy. Over the same period, this successful development has led to a large increase in demand for food, especially for livestock products ${ }^{1,2}$. The import value of agricultural products has increased by $78 \%$ in constant US $\$$ (ref. ${ }^{3}$ ) while domestic agricultural value increased by $36 \%$ from 2010 to 2018 . For soybean products in particular, the reliance on imports increased from $46 \%$ to $83 \%$; for ruminant meat from $2 \%$ to $17 \%$ and for dairy products from $11 \%$ to $24 \%$ (ref. ${ }^{2}$ ). The increasing demand also presents a great challenge to achieving the Sustainable Development Goals $(\mathrm{SDGs})^{4}$ in China and worldwide as the agricultural sector is a key contributor to greenhouse gas (GHG) emissions (SDG 13), air and water pollution (SDGs 3 and 6) and biodiversity loss (SDG 15).

China's domestic crop production increased by $44 \%$ between 2000 and 2018. Cropland expansion (4.9 Mha) (ref. ${ }^{5}$ ) contributed $7 \%$ of production increase, with the remaining $93 \%$ from intensification. As a result, the use of nitrogen fertilizer in China today accounts for $32 \%$ of global fertilizer use. Similarly, livestock production also intensified, with increased reliance on concentrate feeds ${ }^{2}$. China's agricultural production is now responsible for $13 \%$ of global GHG emissions ${ }^{2}$. Air and water pollution have reached 4.2 -fold and 2.7-fold, respectively, of sustainability thresholds $s^{6,7}$ defined by fine particulate matter $\left(\mathrm{PM}_{2.5}\right)$ and nitrogen discharge, largely due to the agriculture intensification. In addition, irrigation water use in China represents $13 \%$ of global water withdrawals, and the efficiency (48\%) has substantial room for improvement compared with the levels in Europe and in North America (55-71\%) (refs. ${ }^{8,9}$ ).
Expanding imports are contributing to environmental pressure in exporting countries. Recent studies showed that displacement of resource use and environmental damage through international trade in the recent past represented a substantial share of the environmental impacts of domestic food production ${ }^{10-12}$. The contribution of China's food demand to the challenge of achieving sustainable development of China's trading partners has also been highlighted. For example, $43 \%$ of deforestation emissions due to soybean cultivation in Brazil can be attributed to China's soybean imports in $2017^{13}$. In addition, GHG emissions embodied in ruminant products exported to China accounted for $17 \%$ of total New Zealand livestock emissions in $2010^{14}$.

China's food demand is projected to keep increasing in the coming decades with further increase in the reliance on food and feed imports ${ }^{15}$. It is therefore necessary to assess the impacts of such growing demand on China's domestic environment as well as the environment of its trading partners to inform sustainable development policies. However, current forward-looking assessments (Supplementary Methods 1) either focused on local impacts only without considering global market spillovers ${ }^{14,16,17}$, covered only a part of the agricultural sector (for example, bioenergy demand and afforestation ${ }^{18,19}$ ) or assessed only one or two environmental dimensions $^{20-22}$. Assessments of future trade patterns mostly present trade with a world pool market ${ }^{23,24}$, making it hard to track global environmental impacts. An integrated assessment simultaneously analysing global agricultural markets and China's bilateral trade, land-use competition and associated environmental impacts in detail and presenting for China separately from other regions is still lacking.

${ }^{1}$ Key Laboratory of Agricultural Water Resources, Hebei Key Laboratory of Soil Ecology, Center for Agricultural Resources Research, Institute of Genetic and Developmental Biology, Chinese Academy of Sciences, Shijiazhuang, China. ${ }^{2}$ University of Chinese Academy of Sciences, Shijingshan District, Beijing, China. ${ }^{3}$ International Institute for Applied Systems Analysis (IIASA), Laxenburg, Austria. ${ }^{4}$ College of Environmental and Resource Sciences, Zhejiang University, Hangzhou, China. ${ }^{5}$ Wageningen Economic Research, Wageningen University and Research, The Hague, the Netherlands. ${ }^{6}$ Department of Earth and Environmental Sciences, University of Leuven (KU Leuven), Heverlee, Belgium. ${ }^{7}$ Department of Global Development, College of Agriculture and Life Sciences \& Cornell Atkinson Center for Sustainability, Cornell University, Ithaca, NY, USA. ${ }^{8}$ Institute of Biological and Environmental Sciences, University of Aberdeen, Aberdeen, UK. ㅌEnvironmental Change Institute, Oxford University, Oxford, UK. 凶e-mail: havlikpt@iiasa.ac.at; malin1979@sjziam.ac.cn 
In this article, we provide a comprehensive assessment of the global environmental impacts of China's future food demand by 2030, the milestone in the UN 2030 Agenda, and up to 2050. The environmental impacts are assessed domestically, and in terms of virtual environmental trade flows with China's economic partners, looking at four environmental impacts: the use of agricultural land (crop harvested area and pasture); GHG emissions from agriculture, forestry and other land uses (AFOLU); the use of synthetic nitrogen fertilizer; and irrigation water use. We quantify these environmental impacts using the Global Biosphere Management Model (GLOBIOM, www.globiom.org), an agricultural- and forest-sector model that has been used extensively for environmental sustainability analysis of the land-based sectors over the past decade ${ }^{25-29}$. For this study, the representation of China's agricultural sector and environmental dynamics was enhanced in the model (Methods and Supplementary Methods 2). The future development assumed in the projections follows the shared socioeconomic pathways (SSPs) ${ }^{30}$ middle-of-the-road scenario, representing a continuation of current socioeconomic and technological trends (the business-as-usual (BAU) scenario). To cover the range of uncertainty in future developments, we also considered two additional socioeconomic scenarios-a restricted-development (RD) scenario and a high-development (HD) scenario-and provided a comprehensive sensitivity analysis with respect to the role of individual scenario driver (Methods). This work was conducted as part of the Food, Agriculture, Biodiversity, Land, and Energy (FABLE) Consortium of country teams that develop integrated pathways towards sustainable land-use and food systems ${ }^{31}$.

\section{Results}

In this section, we first consider the respective contributions of domestic production and international trade to satisfying China's future food demand, then we explore the implications for the domestic environment; implications for the environment by major trading partners are assessed afterwards. This section concludes with a thorough analysis of the main drivers of the forward-looking scenarios and their sensitivity analysis.

China's food demand increasingly relies on imports. China's total demand for agricultural products, including food, feed, biofuel or other use, is projected to increase substantially by mid-century (Fig. 1a). This is reflected in a $13 \%$ increase in per capita calorie demand in the 2050 BAU scenario relative to 2010 and a $6 \%$ increase relative to 2020 (Supplementary Fig. 1). Per capita demand for animal-sourced calories is projected to increase three times as fast, by $45 \%$ compared with 2010 and $23 \%$ compared with 2020 . Total demand for ruminant meat and dairy products is projected to almost double, reaching, respectively, 19 and $68 \mathrm{Mt}$ in 2050. Pig and poultry products drive livestock demand increases, although the increase is projected to level off after 2040 because of a progressively saturated per capita demand and a projected decrease in population. Nevertheless, demand for pig and poultry products remains $30 \mathrm{Mt}$ higher in 2050 compared with 2010 . The increase in the demand for crop products (34\%) is projected to be driven mainly by the additional feed requirements. In particular, the demand for oil crops is projected to expand twofold compared with 2010 and reach $200 \mathrm{Mt}$ in 2050; however, the demand from 2010 to 2020 constituted the major portion $(57 \%)$ of the increase. The demand for cereals is projected to increase from $420 \mathrm{Mt}$ in 2010 to $530 \mathrm{Mt}$ in 2050 , driven mainly by the increase of cereal feed demand (84\%). In terms of other crops, the increase in demand is comparatively slow, only $9 \%$ higher than the 2010 level.

We project that the increasing demand would largely be satisfied by increasing domestic production (25\% for cereals, $33 \%$ for pig and poultry products, $62 \%$ for ruminant meat and $38 \%$ for dairy products, see second row of Fig. 1a). However, the reliance on imports is also projected to increase. The share of imports in total demand is projected to increase from $7 \%$ to $20 \%$ for ruminant meat, from $12 \%$ to $20 \%$ for dairy products and from $54 \%$ to $70 \%$ for oil crops (mostly soybean) between 2010 and 2050. Pig and poultry products rely little on imports, but large imports of oil crops are required for feed. Currently, the pig-farming industry in China is influenced by African Swine Fever, causing a 22\% deviation from the statistics in 2020. We find that these temporary fluctuations will not have substantial impact on long-term projections (see quantitative validation in Supplementary Methods 3 and Supplementary Figs. 2-6).

The patterns of bilateral trade are projected to change in the future. As shown in Fig. 1b, China's imports of soybean products account for $35 \%$ of the global soybean trade, with $45 \mathrm{Mt}$ total imports in 2010, and major trade partners are Brazil and the United States, which each exports similar amounts of soybean to China (18 Mt). In 2050, China is projected to account for $46 \%$ of global soybean trade, and the import quantity is projected to reach $126 \mathrm{Mt}$. But the bilateral trade pattern (53\% import from Brazil and 37\% import from the United States) would differ from that in 2010, which is in line with current status. Imports of dairy products originate mainly from New Zealand (2.7 Mt, or $40 \%$ of total import) and the European Union (1.0 Mt, or $20 \%$ of total import) in 2010. By 2050, China is projected to import an additional $8.0 \mathrm{Mt}$ of dairy products, and its share in global trade would increase from $13 \%$ to $20 \%$. New Zealand remains the major dairy exporter, accounting for $71 \%$ of China's dairy imports in 2050 .

Environmental impacts of China's food demand. In response to the projected increase in China's food demand between 2010 and 2050, the domestic and virtually imported agricultural lands are projected to expand by 25 and $63 \mathrm{Mha}$, respectively (Fig. 2a). Compared with our projections for 2020, the projected increase of virtually imported agricultural land area (21 Mha) would also be higher than that brought into production domestically (6 Mha) until 2050. In 2050, agricultural imports are projected to represent 41 and 77 Mha of crop harvested area and pasture, respectively (Supplementary Fig. 9a). The increase in virtual crop harvested area for imports between 2010 and 2050 is $15 \mathrm{Mha}$, while the domestic crop harvested area remains at the same level. The increase in imported-crop harvested area is due mainly to soybean (77\%), rapeseed $(7.9 \%)$ and wheat (3.9\%). For pasture, the increase in virtually imported land is 49 Mha between 2010 and 2050, which is twice the domestic increase (26 Mha).

In 2050, the increase in domestic GHG emissions from agricultural production (104 $\mathrm{MtCO}_{2}$-equivalent (MtCO2eq) $\mathrm{yr}^{-1}$, Fig. 2b), mostly from the livestock sector, would be fully compensated by the carbon sink from China's ambitious afforestation programmes $\left(205 \mathrm{MtCO}_{2} \mathrm{eq} \mathrm{yr}^{-1}\right.$, see Supplementary Fig. 10 for detailed information on land transition patterns). This means that net domestic GHG emissions from the AFOLU sector in $2050\left(628 \mathrm{MtCO}_{2} \mathrm{eq} \mathrm{yr}^{-1}\right)$ would be lower than the level in $2010\left(809 \mathrm{MtCO}_{2} \mathrm{eq} \mathrm{yr}^{-1}\right)$. We also estimate that China will be responsible for $123 \mathrm{MtCO}_{2}$ eq yr $^{-1}$ of virtually imported GHG emissions in 2050. A total of $86 \%$ of these trade-embedded emissions would be due to the imports of livestock products. Imports of ruminant meat, dairy and oil products would create 85,18 and $12 \mathrm{MtCO}_{2}$ eq yr $^{-1}$ of direct GHG emissions, respectively. Agricultural imports would also lead to large emissions from deforestation globally $\left(23 \mathrm{MtCO}_{2} \mathrm{eq} \mathrm{yr}^{-1}\right.$ in 2050 , Supplementary Fig. 11). As the demand for imports levels off after 2030, deforestation in exporting regions decreases and the changes in deforestation emissions embodied in trade to China become negative by 2050 . It is worth noting that GHG emissions related to China's afforestation programmes are included in total AFOLU-sector emissions for completeness. However, for consistency, they should not be included when comparing with imported effects for consistency 

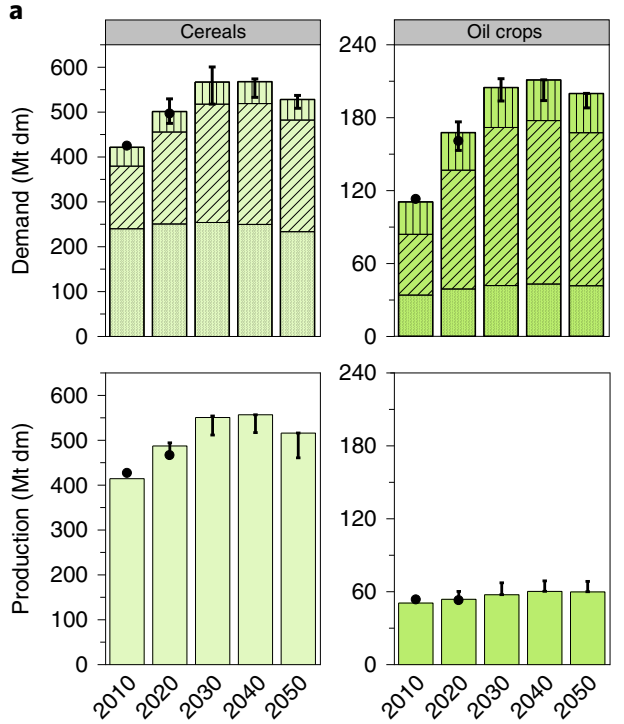
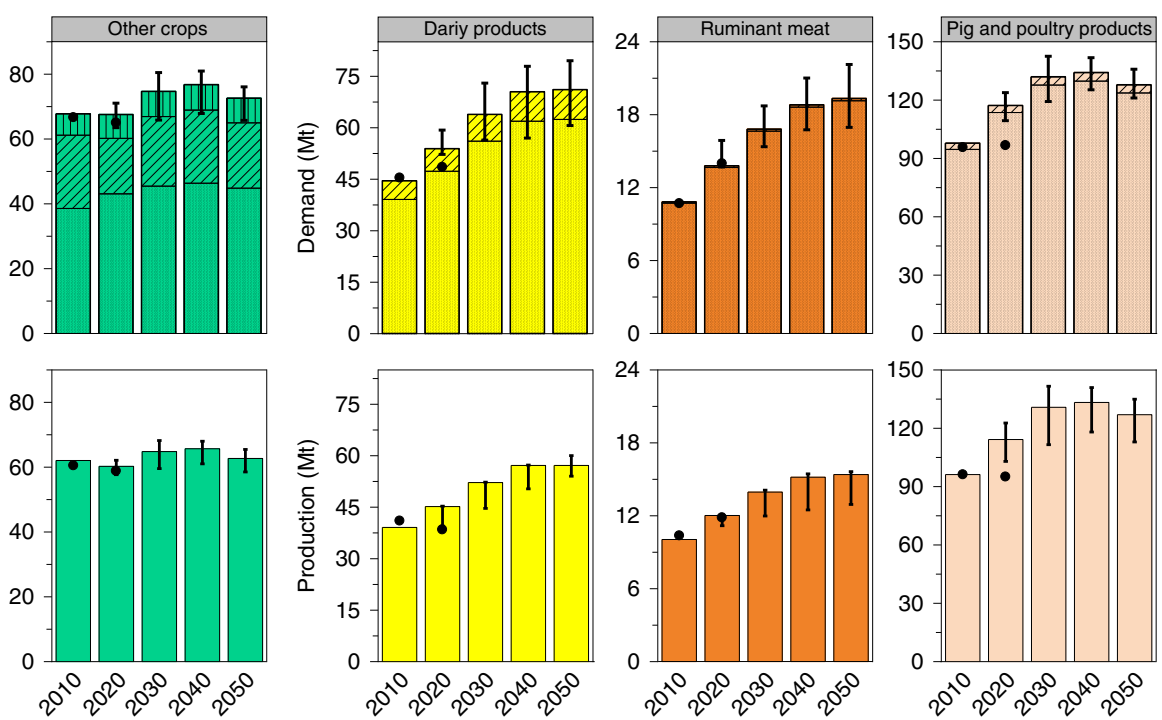

Food use $\mathrm{R} /$ Feed use $\square$ Bio/other use • Statistics

b
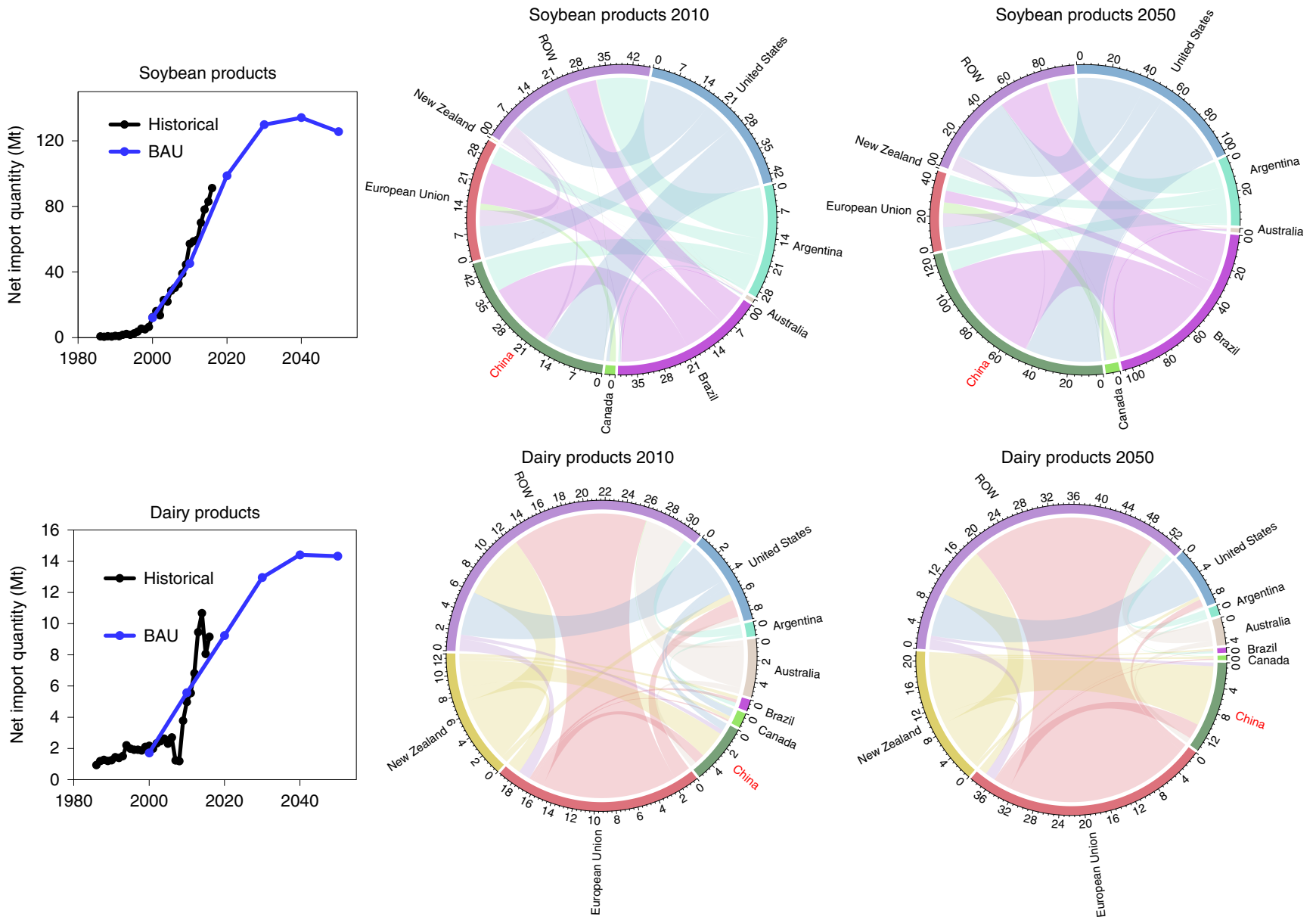

Fig. 1 | Trends in demand, production and trade of agricultural products in China. a, Demand and production patterns, and crop products, are converted to dry matter $(\mathrm{dm})$. The demand is further decomposed into food, feed and biofuel/other use (the first row), while the second row represents domestic

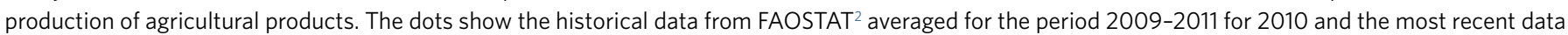
for 2020 from OECD-FAO Agricultural Outlook ${ }^{56}$. Error bars represent the ranges of RD and HD results. For detailed results for individual product categories, see Supplementary Table 1. b. The plots on the left show the trends of net import quantity for dairy and soybean products (see Supplementary Figs. 7 and 8 for more commodities and scenarios). The circular plots in the centre and on the right represent the bilateral trade between China and its major partners in 2010 and 2050, respectively. Each arrow represents the volume of products coming from the exporting region to the importing region and has the same colour as the exporting region. 


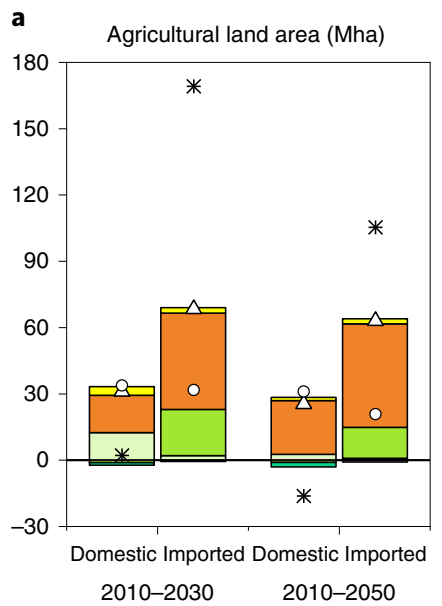

b

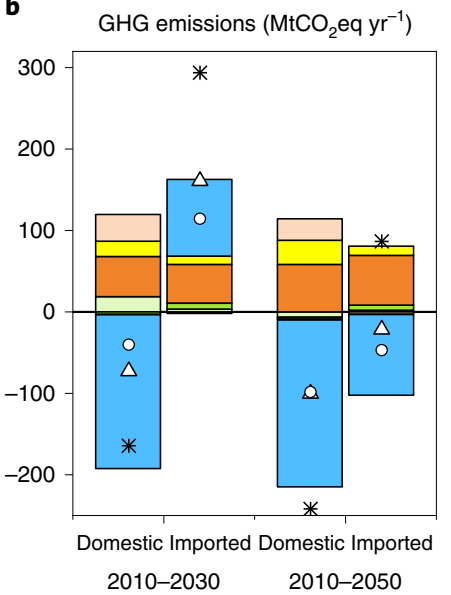

$\square$ Cereals $\square$ Oil crops $\square$ Other crops

$\triangle$ Total change for BAU $\bigcirc$ Total change for RD
Ruminant meat $\square$ Dairy products * Total change for $\mathrm{HD}$ c

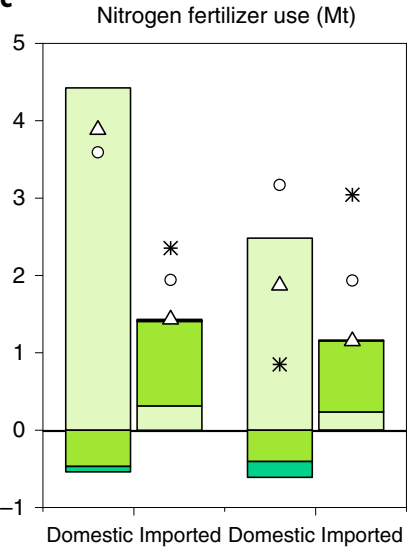

2010-2030

2010-2050 d

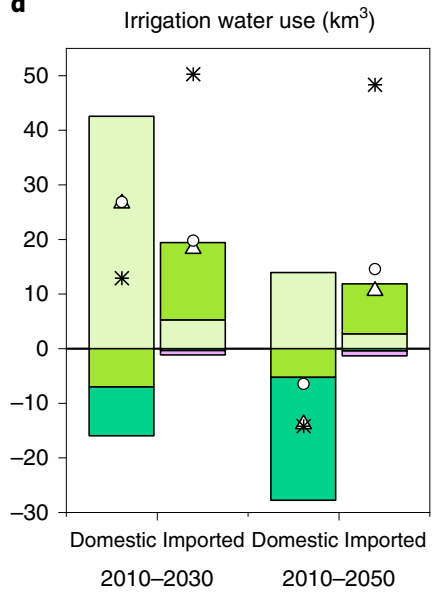

Fig. 2 | Domestic versus virtually imported changes of environmental impacts. a-d, Projected changes in the domestic and virtually imported environmental impacts between 2010 and 2030/2050 for agricultural land (crop harvested area and pasture) (a), GHG emissions (b), nitrogen fertilizer use (c) and irrigation water use (d). The stacked bars represent the decomposed effects by different agricultural products from the BAU scenario, and the markers represent the total effects from the three scenarios (BAU, RD and HD). Detailed environmental impacts from the two alternative scenarios (RD and HD) can be found in Supplementary Figs. 11-13 and Supplementary Discussion 1. For virtually imported land-use change emissions, only deforestation emissions were considered. See Methods for further details on the calculation of the virtual trade flows.

because for imported land-use change emissions, only deforestation emissions were considered.

Increased domestic production requires more inputs and resources: we project a $17 \%$ increase in nitrogen fertilizer use and an additional $25 \mathrm{~km}^{3}$ of irrigation water use in the peak period (2030) in China (Fig. 2c,d). Because China's major import crop, soybean, does not require much nitrogen and irrigation, the virtually imported nitrogen fertilizer and water from trade partners would be less than $9.0 \%$ of overall consumption (Supplementary Fig. 9c,d), but still higher than the present level.

Environmental challenges for China's main trade partners. Most of China's crop-related trade impact (crop harvested area, nitrogen fertilizer and water use) occurs in a few countries with large agricultural sectors, mainly Brazil, the United States and Canada (Fig. 3). Oil crops are highly traded. For example, China is projected to import $66 \mathrm{Mt}$ of soybean from Brazil in 2050, which would account for $40 \%$ of Brazil's soybean production, occupying $16 \mathrm{Mha}$ of crop area and using $0.7 \mathrm{Mt}$ nitrogen fertilizer. Virtual water trade occurs mainly with the United States, where irrigation is widely used to produce cereals and oilseeds. Not only crop products, but also crops embodied as feed in livestock product exports to China, represent additional environmental pressure. In New Zealand, 15\% of nitrogen use and irrigation water use can be attributed to feed use for livestock products exported to China.

The intensity of trade in terms of embodied pasture area depends on the prevalent livestock production system $^{32}$. For example, Australia is projected to export $0.3 \mathrm{Mt}$ of bovine meat to China, which would occupy $14 \mathrm{Mha}$ of pasture in 2050. By comparison, the United States exports an even higher amount of bovine meat to China $(0.5 \mathrm{Mt})$ but at the expense of $4.0 \mathrm{Mha}$ of pasture in 2050 because the intensive grain-based ruminant systems are dominant in the United States, and pasture productivity there is higher than in Australia. With respect to the imports of total virtual GHG emissions, Brazil, New Zealand and Australia carry the main burden, with 30, 21 and $20 \mathrm{MtCO}_{2} \mathrm{eq} \mathrm{yr}^{-1}$, respectively. Bovine meat export accounts for $77 \%$ of virtual trade in GHG emissions from Brazil to China. For Australia, $5.7 \mathrm{MtCO}_{2} \mathrm{eq} \mathrm{yr}^{-1}$ from deforestation emissions and $10 \mathrm{MtCO}_{2} \mathrm{eqyr}^{-1}$ from ruminant production can be allocated to exports to China. Although the virtual trade in GHG emissions is highest in Brazil, it represents only $8 \%$ of Brazil's total AFOLU emissions. In the case of New Zealand, GHG emissions embodied in exports to China, all due to ruminant products, would account for $33 \%$ of the country's total AFOLU emissions in 2050.

Alternative futures. Two alternative socioeconomic scenarios, RD and HD, and their decomposition by individual driver (for example, population, GDP, diet, productivity, trade), provide insights into the robustness of the BAU results in the context of a wide range of alternative plausible futures and to explain the role of each driver. Domestic impacts are less sensitive to the different scenario assumptions than are the trade-mediated impacts (Supplementary Fig. 13). The imported impacts in both scenarios differ considerably compared with those of the BAU in terms of agricultural land and GHG emissions (Fig. 4a), but they represent still substantial worldwide impacts. In the RD scenario, the share of virtually imported land and GHG emissions in China's global environmental impacts reach $26 \%$ and $15 \%$, respectively, and in the HD scenario those numbers could reach $46 \%$ and $31 \%$, respectively. With respect to nitrogen fertilizer and water use, the imported impacts account for less than $10 \%$ of global impacts, except in the HD scenario (around 15\% of imported share).

Openness of trade is the key determinant of the differences in virtual trade flows, in particular for agricultural land (Fig. 4b). The total China-related agricultural land area is $32 \%$ higher in the HD TRADE scenario and 20\% lower in the RD TRADE scenario compared with the BAU projections. This difference is due mostly to the imported impacts; for example, virtual agricultural land area import in the $2050 \mathrm{HD}$ TRADE scenario reaches $288 \mathrm{Mha}$, which is more than twice the BAU value ( $132 \mathrm{Mha})$, whereas restricted trade increases the domestic environmental challenges in China (Supplementary Fig. 14). HD TRADE assumption would lead to a decrease in GHG emissions mainly because of increasing imports from low-GHG-intensity regions compared with China (for example, the European Union and the United States, Supplementary Table 2). Environmental impacts are also sensitive to changes in GDP and population growth, which vary food consumption. 
a
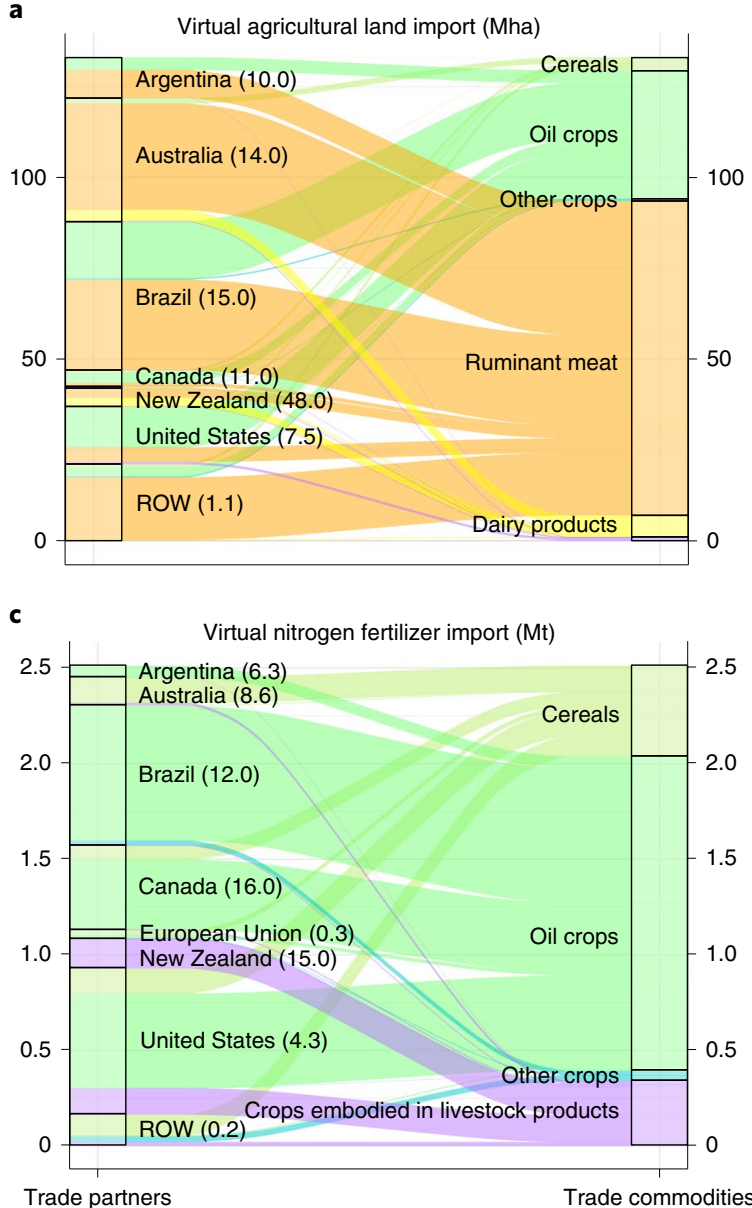

b

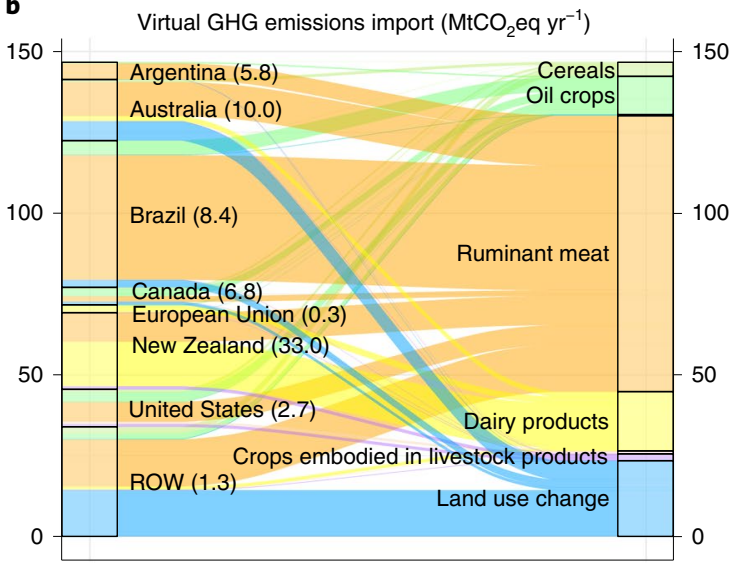

d

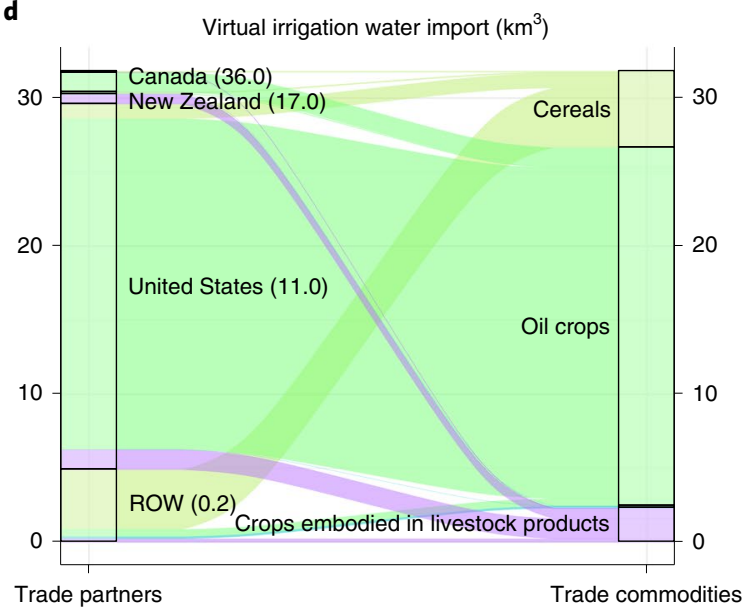

Fig. 3 | Environmental impacts on exporting regions. a-d, Virtual trade flows of environmental impacts due to China's agricultural imports in terms of the agricultural land (crop harvested area and pasture) (a), GHG emissions (b), nitrogen fertilizer use (c) and irrigation water use (d) for the major trading partners and the rest of world (ROW, regions except for China and its seven major partners). The impacts are for 2050 under the BAU scenario. The environmental impacts in the exporting regions are shown on the left, and the sources of environmental impacts by commodity are shown on the right. The numbers in the brackets represent the impacts due to the exports to China as a share of the total environmental impacts of domestic production in the exporting region. For example, virtual agricultural area imports by China from Argentina account for $10 \%$ of Argentina's total agricultural area use.

For GDP growth, RD and HD scenarios differ with the BAU projection on GHG emissions by $-5 \%$ and $+11 \%$, respectively. Population change has an opposite effect, resulting in a difference in emissions with the BAU (+4\% and $-3 \%)$. Shifting diets to more livestock consumption (HD DIET) leads to 7\% more agricultural land and GHG emissions and $3 \%$ more nitrogen fertilizer use. An increase in food waste would also increase nitrogen fertilizer and water use by $3 \%$ as shown in the RD DIET scenario. The impacts of changes in productivity (YILD and FEEF) are less pronounced.

As the assessment has been conducted in a global context, understanding the effects from variations in the socioeconomic development trajectory in China compared with the ROW is also important (Methods). We find that the assumptions on drivers for China dominate the environmental effects. Thus, changes in the driver assumptions for China only (Supplementary Fig. 15a) result in similar environmental effects compared to applying them globally (Fig. 4b). Driver changes in the rest of world (ROW, regions except for China) only (that is, keep the drives for China same as the BAU) have much less influence on China's global environmental impacts $( \pm 3.2 \%$ in Supplementary Fig. $15 \mathrm{~b})$.

\section{Discussion}

Our study, based on a well-established global model with thorough validation for China and its bilateral trade flows, provides a medium to long-term perspective on the potential global environmental impacts of China's increasing food demand. The results have far-reaching implications for China's policies related to food demand, production systems and environmental and resources management, as well as international trade.

There is potential to reduce meat consumption. China's per capita calorie consumption is projected to increase from $2,974 \mathrm{kcal} \mathrm{d}^{-1}$ in 2010 to $3,376 \mathrm{kcal} \mathrm{d}^{-1}$ in 2050 , where livestock products share increases from $19 \%$ to $22 \%$. The projected increase in demand compares well to projections in other studies (Supplementary Table 3). The increasing consumption of ruminant products would require $224 \mathrm{Mha}$ pasture area (59\% domestically) and $514 \mathrm{MtCO}_{2} \mathrm{eq} \mathrm{yr}^{-1}$ GHG emission (80\% domestically) in 2050 . A $10 \%$ increase in livestock consumption would result in 7\% more land and GHG impacts (Supplementary Fig. 16). Therefore, a shift to a less meat-intensive but more diversified diet with healthy food and a low environmental footprint, such as insects, seaweed and plant-based protein substitutes, would bring essential nutrients and reduce the costs for the environment ${ }^{33-35}$. Meanwhile, malnourishment needs to be taken into account. However, changing diets may be a challenge for emerging markets, especially for consumers in China, as currently there is a lack of awareness of the links among meat consumption, health and environmental sustainability ${ }^{36}$. China has recently reiterated, 

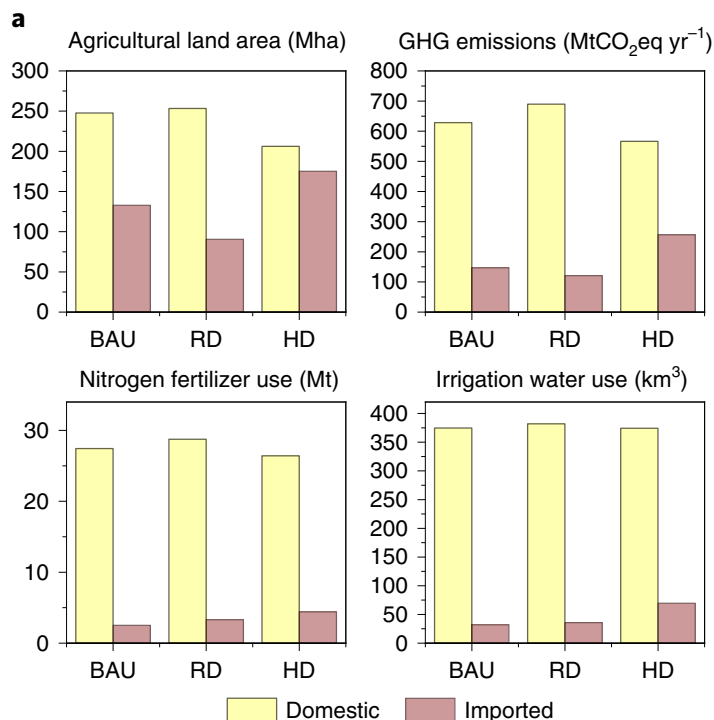

b

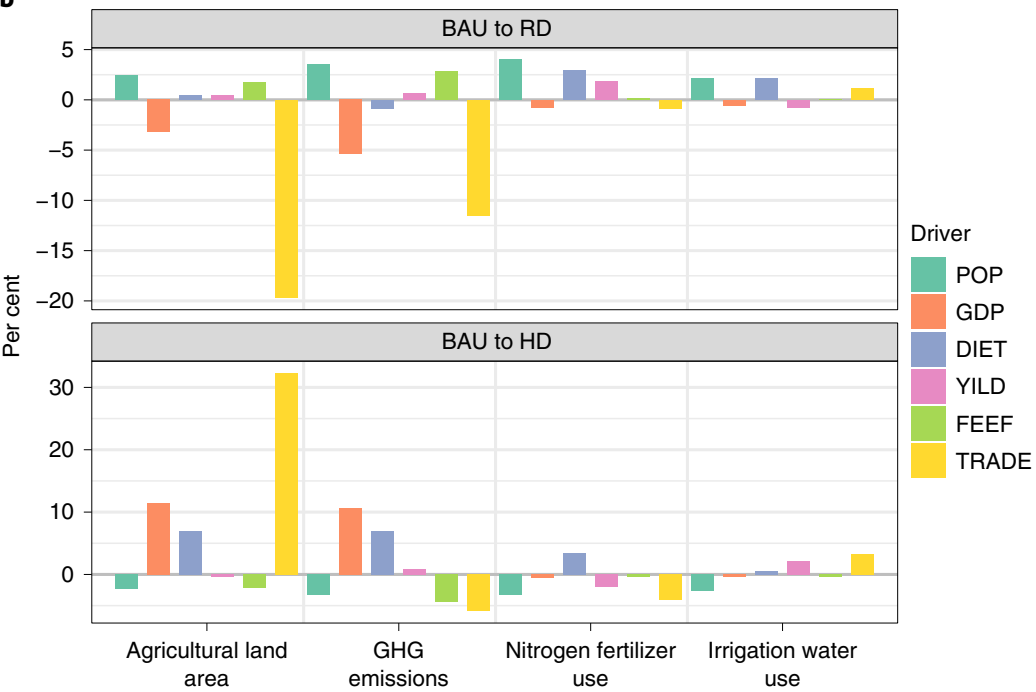

Fig. 4 | Comparison of the global environmental impacts of China's food demand under different scenarios by 2050. a, Environmental impacts in terms of agricultural land (crop harvested area and pasture), GHG emissions, nitrogen use and irrigation water use in the BAU and two alternative scenarios (RD and HD). b. The sensitivity of global environmental impacts to changes in six key drivers. The sensitivity is presented as the relative change of environmental impacts compared with the BAU level due to the changes in the individual key drivers implemented globally. The six key drivers are population (POP), economic development (expressed as gross domestic product (GDP)), consumption preference (DIET), crop productivity growth (YILD), livestock productivity growth (FEEF) and the level of trade integration (TRADE). See Scenario design in Methods for details on the implementation of the sensitivity tests.

through the voice of President Xi, its commitment to drastically reduce food waste, which would bring environmental benefits from the consumer side.

Sustainable livestock production is imperative. Integrated, long-term and large-scale investments have been made in sustainability programmes in China, which have had a considerable positive impact on the promotion of cropland quality, grassland ecological protection and biodiversity conservation ${ }^{37}$. However, the livestock production with high environmental intensities dominates future sustainability outcomes (Supplementary Fig. 9), and it might require stronger policy interventions. In 2050, 50 Mha of harvested crop area in China is projected to produce feed for highly productive livestock systems (Supplementary Fig. 17). In addition to the local feed produced in China, domestic livestock production relies heavily on imported feed crops contributing to environmental degradation and GHG emissions, also domestically. For example, the large amount of imported feeds results in additional manure that could become a source of pollutants because of the disconnection between animal and crop production ${ }^{38}$. Developing marginal land to produce feed and reconnecting livestock production with land should represent a priority.

Our projected livestock production allocation within China follows the current patterns and thus does not have substantial impact on the future country-level environmental outcomes. In reality, however, because of the heterogeneity of China, spatial allocation may have a substantial effect, which can lead to divergent environmental impacts ${ }^{39}$. Careful spatial planning is therefore necessary to exploit the environmental efficiency potentials to facilitate sustainable development. Increasing ruminant productivity is another promising way for reducing environmental pressure since China still has large productivity gaps compared with developed countries (Supplementary Fig. 18). We also find that assumptions about livestock feed efficiency change in the ROW have an important impact on the agricultural land and GHG emissions footprint of Chinese consumption (FEEF in Supplementary Fig. 15b). China could thus reduce its footprint also by promoting productivity improvement in its trading partners.

Sourcing agricultural imports sustainably. Imported environmental impacts vary considerably not only depending on the openness of trade but also depending on the country of origin. For example, milk-related GHG emissions intensity of the European Union is $0.9 \mathrm{kgCO}_{2} \mathrm{eq} \mathrm{kg}^{-1}$ product, whereas in New Zealand it is $1.4 \mathrm{kgCO}_{2} \mathrm{eq} \mathrm{kg}^{-1}$ (Supplementary Table 2), as shown also by other studies $^{40}$. Our results show that increasing openness of trade (HD TRADE scenario) without accompanying measures can lead to both positive and negative impacts on the environment. Higher dairy imports from the European Union and bovine meat from the United States would lead to less GHG emissions relative to the BAU scenario; however, this scenario would also lead to increased beef imports from Latin American countries where land footprints are high (Supplementary Discussion 2). In addition, the past ban on soybean imports from the United States raised concerns about potential substitution with imports from Brazil and the related impacts on deforestation in the Amazon ${ }^{41}$. The environmental considerations need to be taken into account next to economic efficiency and political sensitivities when designing China's trade policies to avoid unintended environmental consequences.

It is also recognized that even within an exporting country, supply chains may widely differ in their environmental impacts ${ }^{42}$. The environmental performance of specific supply chains is promoted, among others, by certification schemes such as 'zero deforestation' beef $^{43}$ or 'fairtrade' labelling ${ }^{44}$. However, the effectiveness of these measures is limited if non-certified production still finds abundant markets. China, as one of the biggest importers, can play a key role in promoting adoption of environmentally friendly production systems in exporting countries by favouring imports of products from certified supply chains and, in general, by enforcing respect of ambitious environmental standards by its trading partners.

In summary, our results show that satisfying China's food demand while achieving environmental sustainability domestically 
and in exporting regions is probably one of the biggest challenges of the coming decades. Carefully designed policies across the whole of China's food system, including consumers, producers and international trade, are necessary to ensure that future demand can be satisfied without destroying the environment. Design of such policies will require models with high spatial resolution recognizing the heterogeneity of production conditions as well as environmental impacts in a country the size of China. Although the role of international trade is a buffer to shocks on the domestic market, in addition to satisfying part of food demand as a stable source, potential consequences of global short-term events will need to be considered. These important aspects would, however, go beyond the scope of our study.

\section{Methods}

This section presents the integrated modelling approach adopted, model developments for enhanced representation of China and model validation. Then the scenario design and the methodology used for sensitivity analysis are introduced. Virtual trade flows calculation is finally described.

Modelling approach. The quantitative analysis presented in our study relied on the GLOBIOM, a bottom-up partial equilibrium economic model designed to represent the key land-use sectors, including crops, livestock, forestry and bioenergy. GLOBIOM is extensively used for assessment of environmental impacts related to agriculture, such as sustainable water use ${ }^{27}$, GHG emissions ${ }^{29}$, land-use change and related biodiversity impacts ${ }^{45}$. The model is particularly suitable for forward-looking assessment of environmental impacts embodied in trade because of its bilateral trade representation ${ }^{28}$. Finally, the model is flexible enough to allow for a detailed representation of a region of interest, in this case China, while still keeping it embodied in the global modelling framework ${ }^{46}$.

The spatial resolution of the supply side relies on simulation units, which are aggregated from 5 to 30 arcmin pixels belonging to the same altitude, slope and soil class and the same country. For the purpose of this study, they were further aggregated to $2^{\circ}$. Commodity markets and international trade are represented for 37 economic regions in this study. Endogenous adjustments in market prices lead to balance among supply, demand and trade for each product and region. The market equilibrium is found through maximization of the sum of consumer and producer surpluses under constraints, such as land- and water-use balances. The model is solved with recursive dynamics in ten-year time steps. Main exogenous drivers of forward-looking scenarios in GLOBIOM are population and economic growth, technological change, dietary preferences and bioenergy demand. Main endogenous variables are market variables, including demand, supply, trade and prices, and environmental variables such as land and water use, GHG emissions and sinks, and nutrient balances.

Data on agricultural regional market variables, including demand and production, are for the base year harmonized with FAOSTAT ${ }^{2}$. The spatially explicit land-use allocation is initialized for 2000 with GLC2000 ${ }^{47}$. The spatially explicit productivity of crops, grasslands, forests and short-rotation tree plantations is estimated together with related environmental parameters (GHG budgets, nutrient and water balance) at the level of the simulation units. For crops, yields under different management systems are calculated with the biophysical Environmental Policy Integrated Climate (EPIC) model ${ }^{48,49}$. For forest parameters, GLOBIOM relies on the outputs of a dynamic forest management model, the Global Forest Model (G4M) ${ }^{50}$. Grassland productivity is obtained by combining results from EPIC and CENTURY biogeochemistry mode ${ }^{25,51}$. Livestock production systems are parameterized with the global database developed by Herrero et $\mathrm{al}^{52}$. A detailed overview of data sources for the environmental indicators used in this study is presented in Supplementary Methods 4 .

GLOBIOM represents international trade through net bilateral trade flows, which allow only one direction of trade flow between two regions. To simulate trade, GLOBIOM uses the Enke-Samuelson-Takayama-Judge spatial equilibrium approach, assuming homogeneous goods (imported and domestic products are the same $)^{53}$. Thereby, GLOBIOM represents international trade through net bilateral trade flows, which allows only one direction of trade flow between two regions. In addition, the region will only import if its domestic price is greater than the price in the exporting country plus the cost of trade. In equilibrium, the difference in price between the importer and exporter equals the cost of trade. Compared with other trade assumptions (for example, Armington, trade can occur in both directions and gross trade is represented), this trade specification allows for new trade flow creation (no observation in the base year) in response to future price changes. As China is the largest importer for agricultural products and many countries strengthen cooperation in promoting trade with China, this approach is more appropriate for this study. Data on bilateral trade in the base year are from the BACI database ${ }^{54}$, and data on tariffs between different countries and commodities are from the MAcMap-HS6 database ${ }^{55}$. Additional information about the model can be found on www.globiom.org.
GLOBIOM-China. For this study, we modified the core GLOBIOM model to improve representation of China. To better capture the recent and future trends in Chinese agriculture, we included mechanisms mimicking relevant policies in place. One of the key drivers of land use in China is afforestation policies initiated in the 1990s. They already led to afforestation of 53 Mha at the cost of cropland, pasture and other land (unmanaged grass/shrubland, non-/sparse vegetation). Considering Chinese consumers' preference for monogastric products and important structural changes in the sector, we calibrated the shift from smallholder to industrial systems for pig and poultry production. Fertilizer use efficiency development was calibrated to represent the 'zero chemical fertilizer growth by 2020 ' policy. We also enforced the self-sufficiency in three major cereal crops of $95 \%$ under the baseline scenario in line with the current trade policies. Supplementary Methods 2 and Supplementary Table 4 present the model improvements in further detail.

Model calibration and validation. A careful model calibration was performed for the period 2000-2020. FAOSTAT data and Chinese national statistical data until 2019/2020, as well as the OECD-FAO Agricultural Outlook projections for China until $2029^{56}$, were then used to validate the model behaviour (Supplementary Figs. 2-7). The validation focused on the following key variables: crop yield, crop area, per capita food consumption, total demand, production and trade. The performance of the model for the very recent past has been quantitatively documented in Supplementary Methods 3. We also provide the interpretation of mismatches caused by recent pandemic outbreaks.

Bilateral trade calibration is of vital importance for this study. In GLOBIOM, future trade flows are determined by commodity prices and trade costs. Trade costs include tariffs, transport costs and a nonlinear trade expansion cost that reflects persistency in trade patterns. Tariffs and transport costs are kept the same as the base year. The trade expansion costs are used in GLOBIOM to represent the capacity constraints slowing down expansion of trade flows in the short term. They can be regarded as investments necessary to expand trading infrastructure. GLOBIOM allows for the appearance of new trade flows, which were not observed in the base year. Exponential function represents the trade cost (equation (1)) when trade flows are observed in the base year; for new trade flows, a quadratic trade cost function (equation (2)) is used:

$$
\begin{aligned}
& \text { Trade } \text { cost }_{t}=\frac{\varepsilon}{1+\varepsilon} \times \frac{\text { Tariff }+ \text { Transport cost }}{\text { Shipment }_{t-1}^{1 / \varepsilon}} \times \text { Shipment }_{t}^{\frac{1}{\varepsilon}+1} \\
& \text { Trade } \operatorname{cost}_{t}=\text { Intercept } \times \text { Shipment }_{t}+0.5 \times \text { slope } \times \text { Shipment }_{t}^{2}
\end{aligned}
$$

Trade costs in period $t$ are calculated with $\varepsilon$ and slope reflecting the elasticity of trade costs to traded quantity in the respective equations. The intercept is equal to the tariff plus transport cost. The bilateral trade flows between China and other countries until 2020 were calibrated to match the recent Food and Agriculture Organization trade matrix statistics ${ }^{2}$ by manipulating the elasticities and slopes in the trade cost equations. The bilateral trade validation of major commodities is shown in Supplementary Fig. 7. Calibration work also benefited from feedback by seven country teams of the FABLE Consortium.

Scenario design. The aim of this study is to provide medium to long-term ex ante assessment of a global business-as-usual scenario aligned with current socioeconomic trends. We complemented this scenario with two variants with contrasted assumptions on future drivers and decompose those drivers to explore the range of results uncertainty. Development of such scenarios at the global level, with consistency across all sectors and regions, is a non-trivial task. Therefore, we decided to rely on the well-established framework of the SSPs, which provide a set of narratives and quantified drivers designed to analyse global trajectories of future development ${ }^{30}$. These pathways represent the backbone of the climate-related scenario analysis within the Intergovernmental Panel on Climate Change (IPCC) ${ }^{57}$ and have recently been used also for forward-looking biodiversity assessment in the context of the Intergovernmental Science-Policy Platform on Biodiversity and Ecosystem Services (IPBES) ${ }^{58}$. We acknowledge that some outbreaks (such as the US-China trade war in 2018 or COVID-19) may cause shocks and obstruct development of trade. However, in general these shocks are short-term disruptions ${ }^{59}$, and our scenarios can cover these large uncertainties.

A BAU scenario following SSP $2^{60}$ that mostly continues recent trends in consumption and technological developments was used as baseline in this study. The two alternative scenarios are (1) the RD scenario and (2) the HD scenario. The RD scenario follows the SSP 3 assumption ${ }^{61}$ where the population in China increases faster, and growth in the GDP is slower, which leads to lower total food demand, in particular lower demand for livestock products compared with BAU. In this scenario, international trade becomes more restricted and fragmented, reflecting lower international cooperation. The HD scenario follows the SSP5 assumption $^{62}$ and orients towards high economic growth but limited resource efficiency, leading to inclusive development but at the expense of the environment. International trade expands rapidly in globalized markets in this scenario. All these scenarios make the assumption of a diverse development trajectory of different regions following their economic growth in per capita change ${ }^{63}$, which are primary drivers for diet shifts and agricultural productivity changes. 
As the food-demand patterns have been aggregated at the country level, income per capita drives changes in food diets ${ }^{64}$. Food prices are also important drivers for food-consumption pattern changes and are determined by demand-price elasticities of food products ${ }^{65}$. The crop yield trends are estimated on the basis of estimation of correlation between yield and scenario-specific GDP growth assumed in the SSPs ${ }^{66}$. In addition, re-allocation of cropland and shift of crop systems endogenously modelled also affect crop yield. For livestock systems, technical change is applied through exogenous assumption on feed conversion efficiencies estimated on the basis of historical trends for the BAU scenario and differentiated for the alternative scenarios on the basis of the average projected crop yield growth ${ }^{67,68}$. Trade assumption is one of the key differences among scenarios. Elasticity or slope of trade costs are varied depending on whether trade flow is observed in the base year. The trade liberalization or restrictiveness ${ }^{28}$ across scenarios reflecting infrastructure, non-tariff trade barriers and regional factor changes determines whether elasticities (slopes) are multiplied or divided by 10 . More information on GLOBIOM trade specification can be found in Janssens et al. ${ }^{28}$. The values of key scenario drivers for China are provided in Supplementary Table 5 , and a detailed description of alternative results can be found in Supplementary Discussion 1.

Considering that our assumptions of future changes (BAU, RD and HD scenarios) are based on a set of drivers (demographic and economic development, dietary preferences, agricultural productivity growth and international trade policies), we conducted a sensitivity analysis in which the impact of individual elements in the RD and HD scenarios is decomposed following the approach by Stehfest et al. ${ }^{69}$. The decomposition was implemented at the (1) global level, (2) ROW level and (3) China level only. This makes it possible to assess the individual impact of the preceding. Demographic development (POP) affects mainly future demand volumes adjusted by price effects. Economic development (GDP) affects income and associated food demand. Dietary preference (DIET) presents differences in dietary patterns between scenarios. Diet shifts and food waste are both included in this dimension. Crop productivity (YILD) is characterized by a different speed of technological changes. Livestock feed conversion efficiency (FEEF) is another key component on the supply side, determining future livestock productivity. Trade development (TRADE) represents the level of integration among global regions. The detailed results of the sensitivity analysis are presented in Supplementary Discussion 1 and Supplementary Figs. 14-16.

Calculating virtual trade flows in environmental impacts. Virtual trade flows refer to resources or pollution embodied in international trade. We focus our analysis about four environmental aspects (land, GHG, irrigation water and nitrogen) on seven major trading partners of China-Argentina, Australia, Brazil, Canada, New Zealand, the United States and the European Union-which account for more than $80 \%$ of the value of China's agricultural imports (Supplementary Table 6). With respect to China trade flows, we also calculated the export effects (Supplementary Table 7); however, since imports dominate the overall trade pattern of China, we allocated the export impacts into the domestic production side. To calculate trade impact, we assume the same environmental intensity of products for domestic consumption and for export in a country. This is the assumption commonly used in many previous studies on virtual trade in water ${ }^{70}$, land $^{71}, \mathrm{GHG}^{10}$ and nitrogen ${ }^{72}$. The environmental intensity in a resource for a specific product $\mathrm{P}$ in exporting region $\mathrm{R}$ and specific year $\mathrm{T}$ is defined as:

$$
\begin{aligned}
& \text { Virtual_area }_{\mathrm{R}, \mathrm{P}, \mathrm{T}}=\text { BilateralT }_{\mathrm{R}, \mathrm{P}, \mathrm{T}} \times \text { Land_intensity }_{\mathrm{R}, \mathrm{P}, \mathrm{T}} \\
& =\text { BilateralT }_{R, P, T} \times \frac{\operatorname{AREA}_{R, P, T}}{\operatorname{PROD}_{R, P, T}} \\
& \text { Virtual_ } \mathrm{N}_{\mathrm{R}, \mathrm{P}, \mathrm{T}}=\text { Bilateral } \mathrm{T}_{\mathrm{R}, \mathrm{P}, \mathrm{T}} \times \mathrm{N}_{-} \text {intensity } \mathrm{R}, \mathrm{P}, \mathrm{T} \\
& =\text { BilateralT }_{\mathrm{R}, \mathrm{P}, \mathrm{T}} \times \frac{\mathrm{N}_{\text {input }_{\mathrm{R}, \mathrm{T}, \mathrm{T}}}}{\mathrm{PROD}_{\mathrm{R}, \mathrm{P}, \mathrm{T}}} \\
& \text { Virtual_water }_{\mathrm{R}, \mathrm{P}, \mathrm{T}}=\text { BilateralT }_{\mathrm{R}, \mathrm{P}, \mathrm{T}} \times \text { Water_intensity }_{\mathrm{R}, \mathrm{P}, \mathrm{T}} \\
& =\text { BilateralT } T_{R, P, T} \times \frac{\text { Water }_{R, P, T}}{\operatorname{PROD}_{R, P, T}} \\
& \text { Virtual_Agri_GHG } \mathrm{R}, \mathrm{P}, \mathrm{T}=\text { BilateralT }_{\mathrm{R}, \mathrm{P}, \mathrm{T}} \times \text { Agri_GHG_intensity }_{\mathrm{R}, \mathrm{P}, \mathrm{T}} \\
& =\text { BilateralT } T_{R, P, T} \times \frac{\text { Agri_GHG }_{R, P, T}}{\text { PROD }_{\text {R,PT }}}
\end{aligned}
$$

where Bilateral $T_{R, P, T}$ is the net bilateral trade quantity $(\mathrm{Mt})$ of product $\mathrm{P}$ exported to China from region $\mathrm{R}$ in year $\mathrm{T}$; $\mathrm{PROD}_{\mathrm{R}, \mathrm{PT}}$ is total production $(\mathrm{Mt})$ of product $\mathrm{P}$ of exporting region $\mathrm{R}$ in the year $\mathrm{T} ; \mathrm{AREA}_{\mathrm{R}, \mathrm{P}, \mathrm{T}}$ is total harvested area (Mha) of product $\mathrm{P}$ in exporting region $\mathrm{R}$.

Virtual nitrogen $(\mathrm{N})$ and water calculations follow the same logic (equations (4) and (5)), where $N_{\text {inputR,P,T }}$ represents synthetic fertilizer use (Mt), and Water $r_{R, P, T}$ represents irrigation water use $\left(\mathrm{km}^{3}\right)$ for product $\mathrm{P}$ of exporting region $\mathrm{R}$ in year $\mathrm{T}$. For nitrogen and irrigation water, we used crop-specific resource intensity informed by EPIC model calculations.
Equation (6) was used to calculate virtual agricultural-related GHG emissions $\left(\mathrm{MtCO}_{2}\right.$ eq yr $\left.{ }^{-1}\right)$. Fertilizer nitrous oxide $\left(\mathrm{N}_{2} \mathrm{O}\right)$ emissions and methane $\left(\mathrm{CH}_{4}\right)$ from rice paddies were considered as direct crop-related $\mathrm{GHG}$ emissions. $\mathrm{N}_{2} \mathrm{O}$ was calculated on the basis of nitrogen fertilizer consumption and IPCC emission coefficients ${ }^{73}$ while rice $\mathrm{CH}_{4}$ was based on FAOSTAT average emission factors ${ }^{2}$. For livestock products, we used emissions intensity parameters for $\mathrm{CH}_{4}$ from enteric fermentation and for $\mathrm{CH}_{4}$ and $\mathrm{N}_{2} \mathrm{O}$ from manure management, manure dropped on pastures, rangelands and paddocks and from the global livestock production systems database ${ }^{52}$

To calculate emissions from deforestation, we rely on a top-down indirect allocation approach ${ }^{74}$. We first determined forest losses in exporting regions on the basis of the G4M model calculations ${ }^{50}$ and then determined the deforestation attributable to cropland and pasture expansion on the basis of Curtis et al. ${ }^{75}$. Then we allocated the cropland deforestation emissions to individual crops on the basis of their contribution to the total cropland area expansion. The pasture-related deforestation was distributed among ruminant products on the basis of the pasture area necessary to cover the grass feed requirements of each livestock production system. Finally, we calculated the share of China's virtual land import within the total area of each agricultural product. The deforestation emissions related to crop or pasture expansion are then calculated on the basis of the following equations:

$$
\begin{aligned}
& \text { Virtual_deforemission } \mathrm{R}_{\mathrm{R}, \mathrm{T}}=\text { Deforemis_crop }_{\mathrm{R}, \mathrm{T}} \times
\end{aligned}
$$



Virtual_deforemission $\mathrm{R}_{\mathrm{R}, \mathrm{T}}=$ Deforemis_live $\mathrm{R}, \mathrm{T}_{\mathrm{T}} \times$

$$
\frac{\Delta \text { Pasture }_{\mathrm{R}, \mathrm{P}, \mathrm{T}}}{\sum_{P=1}^{p} \Delta \text { Pasture }_{\mathrm{R}, \mathrm{P}, \mathrm{T}}} \times \frac{\text { Virtual }^{\text {Pasture }_{\mathrm{R}, \mathrm{P}, \mathrm{T}}}}{\text { Pasture }_{\mathrm{R}, \mathrm{P}, \mathrm{T}}}, \forall \Delta \text { Pasture }_{\mathrm{R}, \mathrm{P}, \mathrm{T}}>0
$$

where Deforemis_crop ${ }_{\mathrm{R}, \mathrm{T}}$ and Deforemis_live ${ }_{\mathrm{R}, \mathrm{T}}$ are deforestation emissions $\left(\mathrm{MtCO}_{2} \mathrm{eq}^{-1} \mathrm{yr}^{-1}\right.$ caused by cropland and pasture expansion in region $\mathrm{R}$ and year $\mathrm{T}$, respectively; only the expanded area is accounted for in $\Delta$ Crop_area $\mathrm{R}_{\mathrm{R}, \mathrm{T}}$; $\frac{\text { Virtual_Crop_area }_{R, P, T}}{\text { Crop_area }_{R, P, T}}$ indicates the virtual crop area embodied in trade, which is presented in equation (3), divided by Crop_area $a_{R, P, T}$ to calculate the share of virtual land import. Similarly, deforestation caused by virtual pasture trade can be derived from equation (8).

Environmental impacts due to feed production are included in the virtual trade flows related to livestock products. For this purpose, we used the specific feed requirements of the regional livestock production specific feed requirements from Herrero et $\mathrm{al}^{52}$. We calculated the total feed use and the related domestic environmental impacts for different livestock products and allocated them proportionally on the basis of the quantities of the bilateral trade to the environmental impacts virtually imported by China. For feed crops embodied in the trade of livestock products, we considered only locally produced feed. This may lead to minor underestimation of the global impact of China's imports, but this should remain minor as many livestock product exporters to China are not major feed crop importers.

\section{Data availability}

The main data supporting the results of this study can be found in the Supplementary Information, and other relevant data are available in the IIASA DARE repository (https://dare.iiasa.ac.at/126/). Source data are provided with this paper.

\section{Code availability}

The code used to present the results in this study is available from the corresponding author upon request.

Received: 3 August 2020; Accepted: 9 September 2021; Published online: 18 October 2021

\section{References}

1. He, P., Baiocchi, G., Hubacek, K., Feng, K. \& Yu, Y. The environmental impacts of rapidly changing diets and their nutritional quality in China. Nat. Sustain. 1, 122-127 (2018).

2. FAOSTAT: Food and Agriculture Data (FAO, 2021); http://www.fao.org/ faostat/en/

3. China's Import and Export of Agricultural Products in 2018 (Ministry of Agriculture, 2019); http://www.moa.gov.cn/ztzl/nybrl/rlxx/201902/ t20190201 6171079.htm

4. Transforming Our World: The 2030 Agenda for Sustainable Development (United Nations, 2015).

5. China Statistical Yearbook (National Bureau of Statistics of China, accessed 1 February 2020); http://www.stats.gov.cn/english/Statisticaldata/AnnualData/

6. Yu, C. et al. Managing nitrogen to restore water quality in China. Nature 567 516-520 (2019) 
7. Zhang, Q. et al. Drivers of improved $\mathrm{PM}_{2.5}$ air quality in China from 2013 to 2017. Proc. Natl Acad. Sci. USA 116, 24463-24469 (2019).

8. AQUASTAT (FAO, 2016); http://www.fao.org/nr/water/aquastat/data/query/ index.html?lang=en

9. Rohwer, J., Gerten, D. \& Lucht, W. Development of Functional Irrigation Types for Improved Global Crop Modelling Report No. 104 (Potsdam Institute for Climate Impact Research, 2007).

10. Caro, D., Lopresti, A., Davis, S. J., Bastianoni, S. \& Caldeira, $\mathrm{K}_{\text {. }} \mathrm{CH}_{4}$ and $\mathrm{N}_{2} \mathrm{O}$ emissions embodied in international trade of meat. Environ. Res. Lett. 9. 114005 (2014).

11. Pendrill, F. et al. Agricultural and forestry trade drives large share of tropical deforestation emissions. Glob. Environ. Change 56, 1-10 (2019).

12. Chen, B. et al. Global land-water nexus: agricultural land and freshwater use embodied in worldwide supply chains. Sci. Total Environ. 613-614, 931-943 (2018).

13. Decoupling China's Soy Imports from Deforestation Driven Carbon Emissions in Brazil (CDP Worldwide, 2019).

14. $\mathrm{Du}, \mathrm{Y}$. et al. A global strategy to mitigate the environmental impact of China's ruminant consumption boom. Nat. Commun. 9, 4133 (2018).

15. OECD-FAO Agricultural Outlook 2019-2028 (OECD, 2019).

16. Ma, L. et al. Exploring future food provision scenarios for china. Environ. Sci. Technol. 53, 1385-1393 (2019)

17. Wittwer, G. \& Horridge, M. A multi-regional representation of China's agricultural sectors. China Agric. Econ. Rev. 1, 420-434 (2009).

18. Zhang, A. et al. The implications for energy crops under China's climate change challenges. Energy Econ. 96, 105103 (2021).

19. Gao, J. et al. An integrated assessment of the potential of agricultural and forestry residues for energy production in China. Glob. Change Biol. Bioenergy 8, 880-893 (2016)

20. Dai, H., Masui, T., Matsuoka, Y. \& Fujimori, S. Assessment of China’s climate commitment and non-fossil energy plan towards 2020 using hybrid AIM/ CGE model. Energy Policy 39, 2875-2887 (2011).

21. $\mathrm{Mi}$, Z. et al. Socioeconomic impact assessment of China's $\mathrm{CO}_{2}$ emissions peak prior to 2030. J. Clean. Prod. 142, 2227-2236 (2017).

22. Yu, Y., Feng, K., Hubacek, K. \& Sun, L. Global implications of China's future food consumption. J. Ind. Ecol. 20, 593-602 (2016).

23. Graham, N. T. et al. Future changes in the trading of virtual water. Nat. Commun. 11, 3632 (2020).

24. Xie, W. et al. Climate change impacts on China's agriculture: the responses from market and trade. China Econ. Rev. 62, 101256 (2020).

25. Havlík, P. et al. Climate change mitigation through livestock system transitions. Proc. Natl Acad. Sci. USA 111, 3709-3714 (2014).

26. Hasegawa, T., Havlík, P., Frank, S., Palazzo, A. \& Valin, H. Tackling food consumption inequality to fight hunger without pressuring the environment. Nat. Sustain. 2, 826-833 (2019).

27. Pastor, A. V. et al. The global nexus of food-trade-water sustaining environmental flows by 2050. Nat. Sustain. 2, 499-507 (2019).

28. Janssens, C. et al. Global hunger and climate change adaptation through international trade. Nat. Clim. Change 10, 829-835 (2020).

29. Frank, S. et al. Structural change as a key component for agricultural non- $\mathrm{CO}_{2}$ mitigation efforts. Nat. Commun. 9, 1060 (2018).

30. O'Neill, B. C. et al. The roads ahead: narratives for shared socioeconomic pathways describing world futures in the 21st century. Glob. Environ. Change 42, 169-180 (2017).

31. Pathways to Sustainable Land-Use and Food Systems (FABLE, 2019).

32. Robinson, T. P. et al. Global Livestock Production Systems (FAO and ILRI, 2011).

33. Willett, W. et al. Food in the Anthropocene: the EAT-Lancet Commission on healthy diets from sustainable food systems. Lancet 393, 447-492 (2019).

34. Parodi, A. et al. The potential of future foods for sustainable and healthy diets. Nat. Sustain. 1, 782-789 (2018).

35. Bonnet, C., Bouamra-Mechemache, Z., Réquillart, V. \& Treich, N. Viewpoint: regulating meat consumption to improve health, the environment and anima welfare. Food Policy 97, 101847 (2020).

36. Zhong, S. \& Chen, J. How environmental beliefs affect consumer willingness to pay for the greenness premium of low-carbon agricultural products in China: theoretical model and survey-based evidence. Sustainability 11, 592 (2019).

37. Bryan, B. A. et al. China's response to a national land-system sustainability emergency. Nature 559, 193-204 (2018).

38. Sun, J. et al. Importing food damages domestic environment: evidence from global soybean trade. Proc. Natl Acad. Sci. USA 115, 5415-5419 (2018).

39. Zuo, L. et al. Progress towards sustainable intensification in China challenged by land-use change. Nat. Sustain. 1, 304-313 (2018).

40. Opio, C. et al. Greenhouse Gas Emissions from Ruminant Supply Chains (FAO, 2013).

41. Fuchs, R. et al. Why the US-China trade war spells disaster for the Amazon. Nature 567, 451-454 (2019).

42. Soterroni, A. C. et al. Expanding the soy moratorium to Brazil's Cerrado. Sci. Adv. 5, eaav7336 (2019).
43. le Polain de Waroux, Y. et al. The restructuring of South American soy and beef production and trade under changing environmental regulations. World Dev. 121, 188-202 (2019).

44. Acquaye, A. A., Yamoah, F. A. \& Feng, K. IntJ. An integrated environmental and fairtrade labelling scheme for product supply chains. Int. J. Prod. Econ. 164, 472-483 (2015).

45. Leclère, $\mathrm{D}$. et al. Bending the curve of terrestrial biodiversity needs an integrated strategy. Nature 585, 551-556 (2020).

46. Soterroni, A. C. et al. Future environmental and agricultural impacts of Brazil's Forest Code. Environ. Res. Lett. 13, 074021 (2018).

47. Bartholomé, E. \& Belward, A. S. GLC2000: a new approach to global land cover mapping from Earth observation data. Int. J. Remote Sens. 26, 1959-1977 (2005).

48. Balkovič, J. et al. Global wheat production potentials and management flexibility under the representative concentration pathways. Glob. Planet. Change 122, 107-121 (2014).

49. Williams, J. R., Jones, C. A., Kiniry, J. R. \& Spanel, D. A. The EPIC crop growth model. Trans. ASAE 32, 0497-0511 (1989).

50. Kindermann, G., McCallum, I., Fritz, S. \& Obersteiner, M. A global forest growing stock, biomass and carbon map based on FAO statistics. Silva Fenn. 42, 387-396 (2008).

51. Parton, W. J. et al. Observations and modeling of biomass and soil organic matter dynamics for the grassland biome worldwide. Glob. Biogeochem. Cycles 7, 785-809 (1993)

52. Herrero, M. et al. Biomass use, production, feed efficiencies, and greenhouse gas emissions from global livestock systems. Proc. Natl Acad. Sci. USA 110, 20888-20893 (2013).

53. Takayama, T. \& Judge, G. G. Spatial and Temporal Price Allocation Models (North Holland Publishing Company, 1971).

54. Gaulier, G. \& Zignago, S. BACI: International Trade Database at the Product-Level. The 1994-2007 Version Working Paper 2010-23 (CEPII, 2010); https://doi.org/10.2139/ssrn.1994500

55. Bouët, A., Decreux, Y., Fontagné, L., Jean, S. \& Laborde, D. Assessing applied protection across the world. Rev. Int. Econ. 16, 850-863 (2008).

56. OECD-FAO Agricultural Outlook 2020-2029 (OECD, 2020); https://doi org/10.1787/1112c23b-en

57. IPCC Special Report on Climate Change and Land (eds Shukla, P. R. et al.) (IPCC, 2019).

58. Diaz, S. et al. Summary for Policymakers. In Global Assessment Report on Biodiversity and Ecosystem Services advance unedited version (IPBES, 2019).

59. Elleby, C., Domínguez, I. P., Adenauer, M. \& Genovese, G. Impacts of the COVID-19 pandemic on the global agricultural markets. Environ. Resour. Econ. 76, 1067-1079 (2020).

60. Fricko, O. et al. The marker quantification of the Shared Socioeconomic Pathway 2: a middle-of-the-road scenario for the 21st century. Glob. Environ. Change 42, 251-267 (2017).

61. Fujimori, S. et al. SSP3: AIM implementation of shared socioeconomic pathways. Glob. Environ. Change 42, 268-283 (2017).

62. Kriegler, E. et al. Fossil-fueled development (SSP5): an energy and resource intensive scenario for the 21 st century. Glob. Environ. Change 42, 297-315 (2017).

63. Shared Socioeconomic Pathways Database v2 (IIASA, 2018); https://tntcat iiasa.ac.at/SspDb

64. Valin, H. et al. The future of food demand: understanding differences in global economic models. Agric. Econ. 45, 51-67 (2014).

65. Muhammad, A., Seale, J. L., Meade, B. \& Regmi, A. International Evidence on Food Consumption Patterns: An Update Using 2005 International Comparison Program Data (USDA, 2011).

66. van Zeist, W. J. et al. Are scenario projections overly optimistic about future yield progress? Glob. Environ. Change 64, 102120 (2020).

67. Valin, H. et al. Agricultural productivity and greenhouse gas emissions: trade-offs or synergies between mitigation and food security? Environ. Res. Lett. 8, 035019 (2013).

68. Herrero, M., Havlik, P., McIntire, J., Palazzo, A. \& Valin, H. African Livestock Futures: Realizing the Potential of Livestock for Food Security, Poverty Reduction and the Environment in Sub-Saharan Africa (Office of the Special Representative of the UN Secretary General for Food Security and Nutrition, United Nations System Influenza Coordination, 2014).

69. Stehfest, E. et al. Key determinants of global land-use projections. Nat. Commun. 10, 2166 (2019).

70. Hoekstra, A. Y. \& Hung, P. Q. Globalisation of water resources: international virtual water flows in relation to crop trade. Glob. Environ. Change 15, 45-56 (2005).

71. Würtenberger, L., Koellner, T. \& Binder, C. R. Virtual land use and agricultural trade: estimating environmental and socio-economic impacts. Ecol. Econ. 57, 679-697 (2006).

72. Huang, G. et al. The environmental and socioeconomic trade-offs of importing crops to meet domestic food demand in China. Environ. Res. Lett. 14, 094021 (2019)

73. IPCC IPCC Guidelines for National Greenhouse Gas Inventories (IPCC, 2006). 
74. Sandström, V. et al. The role of trade in the greenhouse gas footprints of EU diets. Glob. Food Sec. 19, 48-55 (2018).

75. Curtis, P. G., Slay, C. M., Harris, N. L., Tyukavina, A. \& Hansen, M. C. Classifying drivers of global forest loss. Science 361, 1108-1111 (2018).

\section{Acknowledgements}

We acknowledge support from UN Sustainable Development Solutions Network (SDSN)-A. Mosnier, J. Poncet and G. Schmidt-Traub-who initiated this project in the context of FABLE, accompanied it throughout its duration and provided many valuable comments. L.M. acknowledges support from the National Natural Science Foundation of China, NSFC (31972517); the Youth Innovation Promotion Association, CAS (2019101); Key Laboratory of Agricultural Water Resources, CAS (ZD201802); the Outstanding Young Scientists Project of Natural Science Foundation of Hebei (C2019503054). This research has also received funding from the Gordon and Betty Moore Foundation, Norwegian International Climate and Forest Initiative and World Resources Institute. Finally, H.Z. acknowledges IIASA’s Young Scientists Summer Program for providing collaboration opportunities.

\section{Author contributions}

H.Z., P.H. and L.M. designed the study. H.Z., J.C., P.H., M.v.D. and H.V. contributed the data analysis. H.Z., J.C. and P.H. wrote the manuscript with contributions from H.V. and
C.J. All authors contributed to the interpretation of the results and commented on the manuscript.

\section{Competing interests}

The authors declare no competing interests.

\section{Additional information}

Supplementary information The online version contains supplementary material available at https://doi.org/10.1038/s41893-021-00784-6.

Correspondence and requests for materials should be addressed to Petr Havlík or Lin Ma.

Reprints and permissions information is available at www.nature.com/reprints. Publisher's note Springer Nature remains neutral with regard to jurisdictional claims in published maps and institutional affiliations.

Peer review Information Nature Sustainability thanks Guolin Yao and the other, anonymous, reviewer(s) for their contribution to the peer review of this work.

(c) The Author(s), under exclusive licence to Springer Nature Limited 2021 